\title{
Reducing Disaster Risk through Vulnerability Assessment: An Agricultural Perspective
}

Koos van Zyl

\section{Introduction}

A growing population, economic and environmental losses due to natural or human-made disasters, provides the need for a systematic approach to the management of risks. It is generally accepted that a multi-disciplinary understanding of disaster risk management is required.

The ISDR (2002:25) defines disaster risk reduction as "the systematic development and application of policies, strategies and practises to minimise vulnerabilities and disaster risks throughout a society, to avoid (prevent) or to limit (mitigate and prepare) adverse impacts of hazards, within the broader context of sustainable development".

Vulnerability on the one hand means the degree to which an individual, a household, a community or an area may be adversely affected by a disaster. On the other hand resilience is a measure of the capacity to absorb and recover from the impact of a hazardous event. Traditional resilience is common in the Less Developed Countries (LDCs) where disaster is a "normal" part of life and group coping strategies are important.

Disaster risk management seeks to reduce the vulnerability of those communities most at risk through improved access to services, development opportunities, information, education and empowerment. It also seeks to enable communities at all levels to uphold the optimal use, conservation and protection of the natural resources of the country. 
This brought about a focus area for scientific endeavours to achieve a better understanding of the hazards that shape our natural and built environments, to set standards to bring about a safer world, for example, interpreting the early warning signals of natural phenomena, similarly involving risk reduction measures contingency planning and response to emergency events triggered by both natural and non-natural forces within the agricultural sector.

\section{Vulnerability of Agriculture}

\section{Factors impacting on the vulnerability}

In order to understand the vulnerability of agriculture it is necessary to recognise a number of risks and hazards that can result in disasters, each with its own peculiar characteristics.

The following provides an exposition in this respect:

- Although drought is a normal phenomenon worldwide it is often one the most common and devastating disasters South Africa has to face. Flooding is the most common environmental hazard worldwide, costing the most lives after disease and transport accidents.

- In line with current observed climatic conditions, global warming will not only bring significant changes in the world's climate, but, could also have significant effects on various sectors of South African society and the economy.

- In comparison with other countries the South Africa has relatively lowpotential soils, a dry and unstable climate, and a high-cost economy. These factors make it very difficult for South African to be globally competitive and profitable major producers of the world such as the US, EU, Argentina and Brazil.

- Diseases like foot and mouth, swine fever and bird flu, as well as a variety of diseases and pests like locusts, red-billed finches and others are confronting animal health, horticulture and field crops.

- As the share of urban population in South Africa currently reaches 58\%, which is well above the Sub-Saharan Africa average of $34 \%$, South Africa is becoming progressively more urbanised, which is quite consistent with the trends in the developing world. Population growth and urbanisation in is an increasingly important factor to consider in policymaking. 
- Poverty forces the adoption of unsustainable land-use practices whilst it is common knowledge and countries with a legacy of deforestation, soil erosion and over-cultivation, find their environment more vulnerable to environmental hazards like floods and droughts.

- Agriculture faces budget constrains with respect to research and technology developments to cope with disasters. South Africa being a partner to the Johannesburg Plan of Action of the World Summit on Sustainable Development in Johannesburg in 2002 will have to commit funds to deal with environmental degradation and disasters especially as far as climate change is concerned.

- Global interdependence and the functioning of the world economy works against the LDCs. Most of the Third World's export earnings come from its primary commodities for which market prices have either fallen over several decades, or remain highly unstable. The LDCs have little opportunity to process and market what they produce and are dependent on manufactured goods from the industrialised nations that are often highly priced or tied to aid packages.

- Commitment to prevent and mitigate actions that will reduce the probability and severity of disaster events through stepping up awareness campaigns to communities at risk, are largely absent at present. Actions should be incorporated into existing and future policies, plans and projects of national, provincial and local government, as well as policies and practices of the private sector.

- Inequality, associated with the widening economic gap between rich and poor, is closely related to disaster vulnerability

\section{Risk Reduction Measures in Relation to the Agricultural Sector}

In a Study on A Disaster Risk Management Plan for the Agricultural Sector, it was established that by applying the core principles of assessment, prevention, mitigation and preparedness as part of disaster risk reduction measures, as advocated in The Disaster Management Act, 2002 and the Key Performance Areas and Enablers of the National Disaster Risk Management Framework, many disasters in the Agricultural environment can either be reduced or prevented. 
The study's main sentiment was to acquaint the Agricultural Sector with the principles of disaster risk management as perceived in the world at large and in particular within the South African Government. Organised agriculture identifies the need for such a study and provides support throughout. The work that lies ahead will be to align the structures of Organised Agriculture with those structures prescribed by the Disaster Management Act 2002, at the different tiers of Government. Further steps is to transform the principles in workable strategies for the various Commodity Groupings such as Grain, Horticulture and Livestock, as well as an input to Government which will reflect the viewpoints of Organised Agriculture on disaster risk management.

\section{Conclusions}

The promotion of a "culture of prevention" is practically enabled by access to examples of best practice in disaster risk reduction. In addition to the adoption of such measures training and capacity-building strategies, mechanisms for disseminating information on best practice in disaster risk reduction can "make a difference" especially in South Africa where it is much needed as a integrated function of all activities. This includes the development of learning material and support guides for different risk scenarios and contexts for the agricultural sector. 


\section{References}

SOUTHERN AFRICAN DEVELOPMENT COMMUNITY (SADC). 2001. SADC

Disaster Management Strategy. Gabarone: SADC.

SOUTH AFRICA (REPUBLIC). 2003. Disaster Management Act No 57 of 2002.

Pretoria: Government Printer.

SOUTH AFRICA (REPUBLIC). 1999. White Paper on Disaster Management.

Pretoria: Government Printer.

UNITED NATIONS DEVELOPMENT PROGRAMME (UNDP). 2004. Reducing Disaster Risk: A Challenge for Development. New York: John S. Swift Co.

UNITED NATIONS DEVELOPMENT PROGRAMME (UNDP). 1992 An Overview of Disaster Management. Geneva: UNDP-DMTP.

UNITED NATIONS INTER-AGENCY SECRETARIAT OF THE INTERNATIONAL STRATEGY FOR DISASTER REDUCTION (UN/ISDR). 2003. Living with Risk:

Turning the tide on disasters towards sustainable development. Geneva: ISDR.

SMITH, K. 2004. Environmental Hazards.

VON KOTZE, A. 1999b. Learning from Risk Reduction (In Risk, Sustainable Development and Disasters Southern perspectives. Cape Town: Periperi Publications.)

WORLD BANK, 2003. The Millennium Development Goals. [Web: http://www.developmentaoals.ora/Sub-Saharan_Africa.htm]. [Date of access: 30 August 2004].

VAN NIEKERK, D. 2006. A Comprehensive Framework to Guide and Monitor Multisphere Disaster Risk Reduction in South Africa. 
VAN ZYL, KOOS, AUGUST 2006. A Study on a Disaster Risk Management Plan for the South African Agricultural Sector. 